14 Hammer ME, Harding S, Wynn P. Post-traumatic fungal endophthalmitis caused by Exophiala jeanselmei. Ann Ophthalmol 1983; 15: 853-5.

15 Margo CE, Polack FM, Mood CI. Aspergillus panophthalmitis complicating treatment of pterygium. Cornea 1988; 7: 2859.

16 Rodrigues MM, MacLeod D. Exogenous fungal endophthalmitis caused by Paecilomyces. Am F Ophthalmol 1975; 79: 687-90.

17 Slomovic AR, Forster RK, Gelender H. Lasiodiplodia theo- bromae panophthalmitis. Can f Ophthalmol 1985; 20: 225-8. 18 Hanish SJ, Perlmutter JC, Boucher C, Bohigian G, Grand MG Exogenous Aspergillus endophthalmitis. Ann Ophthalmol 1984; 16: 417-9.

19 Ho PC, Tolentino FI, Baker AS. Successful treatment of exogenous aspergillus endophthalmitis: a case report. Br f Ophthalmol 1984; 68: 412-5.

20 Rowsey JJ, Acers TE, Smith DL, Mohr JA, Newsom DL, Rodriguez J. Fusarium oxysporum endophthalmitis. Arch Ophthalmol 1979; 97: 103-5.
Moorfields Eye Hospital, City Road, London EC1V 2PD

J D Steven

A M P Hamilton

Correspondence to:

Julian D Stevens, FCOphth,

Moorfields Eye Hospital, City

Road, London ECIV 2PD.

Accepted for publication

2 February 1993

\section{Displaced intraocular lens repositioning using a reversed 10-0 straight polypropylene needle lasso technique}

\author{
J D Stevens, A M P Hamilton
}

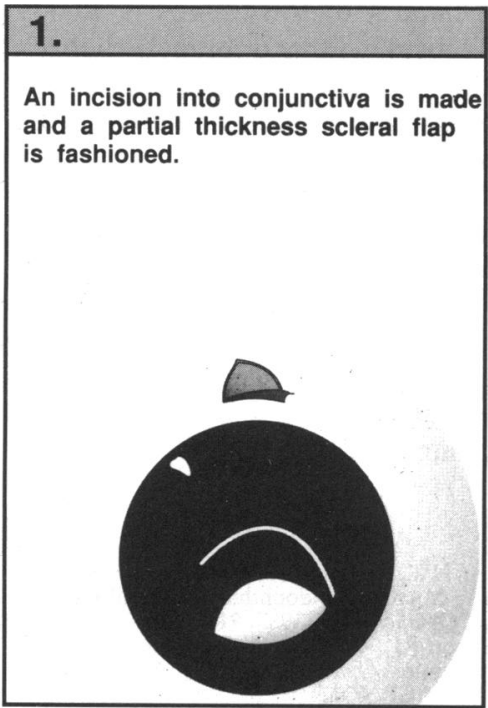

\section{3.}

A 10-0 prolene suture on a straight needle is taken and entered in a reverse fashion through the sclerostomy.

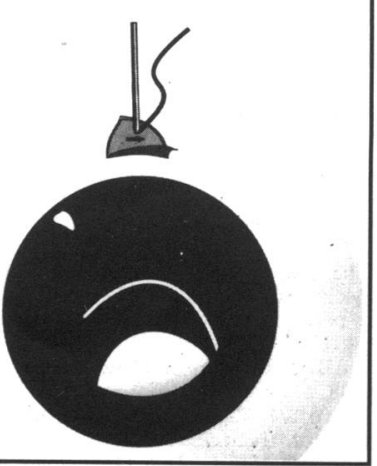

Figure

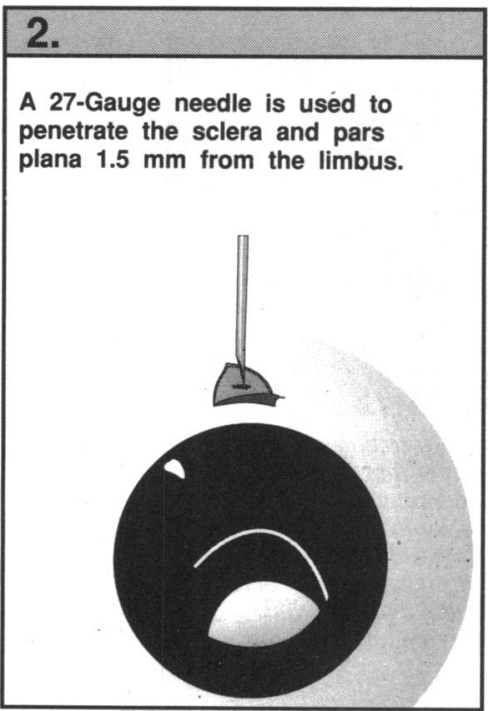

\section{4.}

The $10-0$ prolene suture is advanced behind the iris to loop the superior haptic of the intraocular lens.

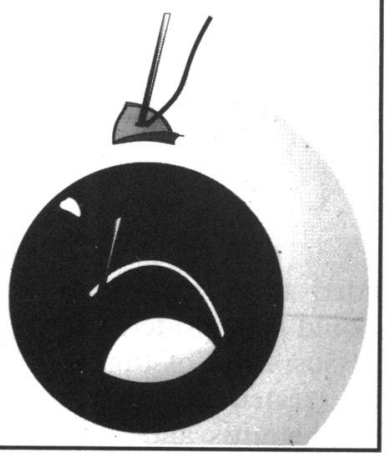

Displacement of a posterior chamber intraocular lens (PC-IOL) may be a serious complication ${ }^{1}$ and surgical repositioning or replacement may be required. Repositioning of a PC-IOL with suture fixation may be necessary and a number of techniques have been described. ${ }^{2-7}$ Recently, pars plana entry site techniques have used vitrectomy with PC-IOL repositioning through a single sclerostomy incision. ${ }^{8}$ We have employed a reverse suture technique using a straight needle, which is easily manipulated and allows rotational lassoing within the eye. Repositioning and suture fixation are performed using only one sclerostomy entry site.

\section{Case reports}

CASE 1

A man with previous ocular blunt trauma, angle recession, and cataract underwent left extracapsular cataract extraction with PC-IOL implantation. Absent zonules were noted from 1 to 3 o'clock and anterior vitrectomy was performed with a PC-IOL placed into the ciliary sulcus with haptics at 5 and 11 o'clock. Fixation was not stable, however, the PC-IOL being displaced inferiorly on the first postoperative day with the superior lens haptic visible in the pupil. The lens was repositioned by the reverse suture technique (see Fig) using a 10-0 polypropylene suture (13049 Lewis SC-5/AUM 10-0 12 inch polypropylene, Alcon) mounted on a straight needle. This was successful, with $6 / 9$ best visual acuity and good lens centration, which has been maintained over a 9 month postoperative review period.

\section{CASE 2}

A man had extracapsular cataract extraction with 
PC-IOL implantation complicated by vitreous loss. Anterior vitrectomy was performed and a PC-IOL implanted with good initial result, but after 8 weeks the lens was displaced inferiorly. Only the superior haptic loop was visible in the undilated pupil. The reversed suture technique was used to draw the PC-IOL upward, entry being $1.0-1.5 \mathrm{~mm}$ posterior to the limbus. ${ }^{9}$ The lens was found to be free of vitreous adhesion, so vitrectomy was unnecessary. Excellent centration was achieved, and at the first postoperative day visual acuity was $6 / 6$ unaided.

\section{Comment}

This technique of repositioning and fixating the
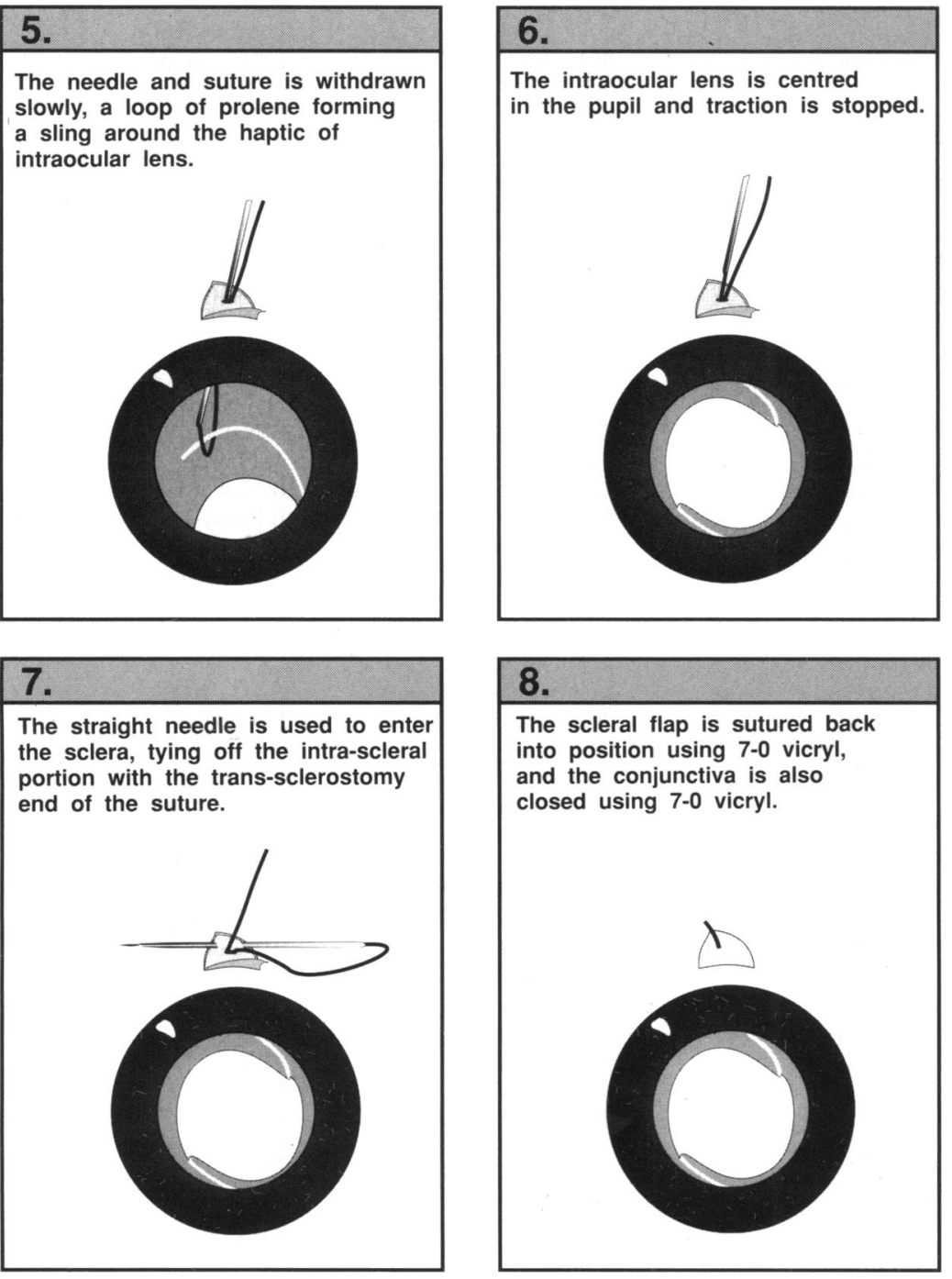

haptic of a PC-IOL is suitable where a loop is visible in the pupil and can be lassoed by the 10-0 polypropylene suture. The needle shaft facilitates guiding of the polypropylene suture over the haptic and simple rotation of the needle with twisting of the polypropylene noose, allows gentle traction to be applied. A curved needle shaft cannot be so easily rotated in such a fashion within the eye. Controlling the straight needle shaft may become difficult if the length of needle shaft within the eye is long and fixation is upon the very tip of the needle shaft.

In both cases, anterior vitrectomy was not performed at the time of repositioning since it had already been completed at the time of PCIOL implantation. In the first case, owing to the presence of angle recession, the external entry site was $1.5 \mathrm{~mm}$ posterior to the limbus to aim for suture fixation at the ciliary sulcus.

The burying of the polypropylene suture under a scleral flap attempts to minimise risk of potential fistula formation between the posterior chamber and the subconjunctival space. A permanent polypropylene foreign body track through from subconjunctival space to inside the globe has implications for potential infection. ${ }^{10}$ Covering the polypropylene by the scleral flap entombs the suture from the ocular surface.

For a displaced PC-IOL, where the end of the lens haptic is visible through the dilated pupil, the technique described offers a closed method for repositioning and fixation by a sling loop. It seeks to minimise risk to the patient by performing repositioning and fixation as a closed procedure.

1 Apple DJ, Mamalis N, Loftfield K, Goodge JM, Novak LC, Kavka-Van Norman D, et al. Complications of intraocular lenses. A historical and histopathological review. Suro Ophthalmol 1984; 29 : 1-54.

2 McCannel MA. A retrievable suture idea for anterior uveal problems. Ophthalmic Surg 1976; 7: 98-103.

3 Stark WJ, Bruner WE, Martin NF. Management of subluxated posterior-chamber intraocular lenses. Ophthalmic Surg 1982; 13: 130-3.

4 Stark WJ, Michels RG, Bruner WE. Management of posteriorly dislocated intraocular lenses. Ophthalmic Surg 1980; 11: 495-7.

5 Campo RV, Chang KD, Okakawa RT. Pars plana vitrectomy in the management of dislocated posterior chamber lenses. in the management of dislocated pos

6 Bloom SM, Wyszynski RE, Brucker AJ. Scleral fixation suture for dislocated posterior chamber intraocular lens. suture for dislocated posterior

7 Anand RA, Bowman RW. Simplified technique for suturing dislocated posterior chamber intraocular lens to the ciliary sulcus. Arch Ophthalmol 1990; 108: 1205-6.

8 Friedberg MA, Pilkerton R. A new technique for repositioning and fixating a dislocated intraocular lens. Arch Ophthalmol 1992; 110: 413-5.

9 Duffey RJ, Holland EJ, Agapitos PJ, Lindstrom RL. Anatomic study of transsclerally sutured intraocular lens implantation. Am $\mathcal{f}$ Ophthalmol 1989; 108: 300-9.

10 Heilskov T, Joondeph BC, Olsen KR, Blatikenship GW. Late endophthalmitis after transscleral fixation of a posterior chamber intraocular lens. Arch Ophthalmol 1989;107: 1427. 